\title{
The impact of nationally distributed guidelines on the management of paracetamol poisoning in accident and emergency departments
}

\author{
M C Bialas, R J Evans, A D Hutchings, G Alldridge, P A Routledge
}

\begin{abstract}
Objective-To assess the impact of the treatment guidelines on the management of paracetamol self poisoning in accident and emergency (A\&E) departments.

Methods-24 A\&E departments in Wales and England provided details of their management of paracetamol poisoning before and after the distribution of national treatment guidelines to all A\&E departments in the United Kingdom.

Results-Significant increases were seen in the availability of formal written policies, the display of treatment nomograms, the recommendation to treat beyond 16 hours after ingestion, and to use a lower line on the treatment nomogram for patients at special risk of paracetamol induced liver damage.

Conclusions-Regularly updated guidelines in the management of paracetamol poisoning should be displayed in $A \& E$ departments so that medical and nursing personnel have access to the best current information on the treatment of poisoning with this frequently used drug.

$(\mathcal{A}$ Accid Emerg Med 1998;15:13-17)
\end{abstract}

Keywords: paracetamol; poisoning

Welsh National Poisons

Unit, Llandough

Hospital, Cardiff, UK

M C Bialas

A D Hutchings

G Alldridge

P A Routledge

Accident and

Emergency

Department, Cardiff

Royal Infirmary,

Newport Road,

Cardiff, UK

R J Evans

Correspondence to:

P A Routledge, UWCM

Therapeutics and Toxicology

Centre, University of Wales

College of Medicine,

Academic Centre,

Llandough Hospital, Cardiff

CF64 2XX, UK.

Accepted for publication 21 July 1997 distribution of formal treatment guidelines

CI, confidence interval
Toxicology Group (which included the directors of the National Poisons Information Services) in October 1992. This was circulated to accident and emergency ( $A \& E$ ) departments throughout the United Kingdom in collaboration with the British Association for Accident and Emergency Medicine. Very similar guidelines had already been produced and distributed on a regional basis by the Welsh National Poisons Unit just before this.

These guidelines take into account evidence supporting the use of a reduced threshold for antidotal treatment in patients where the use of enzyme inducing drugs or regular alcohol consumption in excess of currently recommended amounts increases the risk of liver damage at lower plasma paracetamol concentrations. ${ }^{23}$ They also recognise the safety and value of $\mathrm{N}$-acetylcysteine administration beyond the traditional 15 hour limit after ingestion, particularly if liver damage is severe. ${ }^{4-6}$

To assess the impact of the treatment guidelines we compared departmental policies regarding the management of paracetamol self poisoning in $\mathrm{A} \& \mathrm{E}$ departments in Wales and England, both before and after guideline circulation.

\section{Methods}

In September 1992, 28 A\&E departments in Wales and England commonly requesting advice on poisoning from the Welsh National Poisons Unit in Cardiff were asked to provide details of any current written policy concerning the management of paracetamol self poisoning and to indicate whether a treatment nomogram was available in the department. Copies of policies and nomograms were also requested, with strict assurances made with regard to the confidential nature of the study.

In April 1995 the same requests were made of the 24 departments which had responded to the original survey.

Table 1 Management of paracetamol poisoning in 24 accident and emergency departments before and after the

\begin{tabular}{lllll}
\hline & 1992 before & 1995 after & \multicolumn{2}{c}{ Difference in percentage (95\% CI) } \\
\hline Formal written policy availability & $10(42 \%)$ & $23(96 \%)$ & 54 & $(36$ to 78$)$ \\
Treatment line displayed & $20(83 \%)$ & $24(100 \%)$ & 17 & $(2$ to 32$)$ \\
Treatment after 16 h recommended & $5(21 \%)$ & $22(92 \%)$ & 71 & $(51$ to 91$)$ \\
Special risk line & $4(17 \%)$ & $24(100 \%)$ & 83 & $(68$ to 98$)$ \\
\hline
\end{tabular}


Table 2 Source of treatment nomogram used by accident and emergency departments (1992)

\begin{tabular}{lllll}
\hline Source & $\begin{array}{l}\text { Number of } \\
\text { departments }\end{array}$ & $\begin{array}{l}4 \mathrm{~h} \text { level } \\
(\mathrm{mg} / \text { litre })\end{array}$ & $\begin{array}{l}15 \mathrm{~h} \text { level } \\
(\mathrm{mg} / \text { litre })\end{array}$ & $\begin{array}{l}\text { 10 h level } \\
\text { (mg/litre) }\end{array}$ \\
\hline Manufacturers of acetylcysteine & 10 & 200 & 30 & \\
Textbooks and journals & 4 & 200 & 30 & \\
In house nomogram & 3 & 200 & 30 & 100 \\
Textbook & 1 & 225 & - & 30 \\
In house nomogram & 1 & 160 & - & \\
In house nomogram & 1 & 80 & 30 & \\
No nomogram & 4 & & &
\end{tabular}

Table 3 Source of treatment nomogram (1995)

\begin{tabular}{llll}
\hline Source & $\begin{array}{l}\text { Number of } \\
\text { departments }\end{array}$ & $\begin{array}{l}4 \mathrm{~h} \text { level } \\
(\mathrm{mg} / \text { litre })\end{array}$ & Treatment recommendations \\
\hline National guidelines & 20 & 200 & Treatment up to 24 h \\
In house nomogram & 1 & 200 & Treatment up to 24 h \\
In house nomogram & 2 & 200 & No treatment beyond $16 \mathrm{~h}$ \\
In house nomogram & 1 & 150 & No treatment beyond $16 \mathrm{~h}$ \\
\hline
\end{tabular}

Results

The results of the study are summarised in table 1 .

1992: BEFORE AVAILABILITY OF NATIONAL GUIDELINES

Twenty four of 28 departments responded. Only 10 of the 24 had a formal written policy regarding the management of paracetamol poisoning, two of which required contact with a

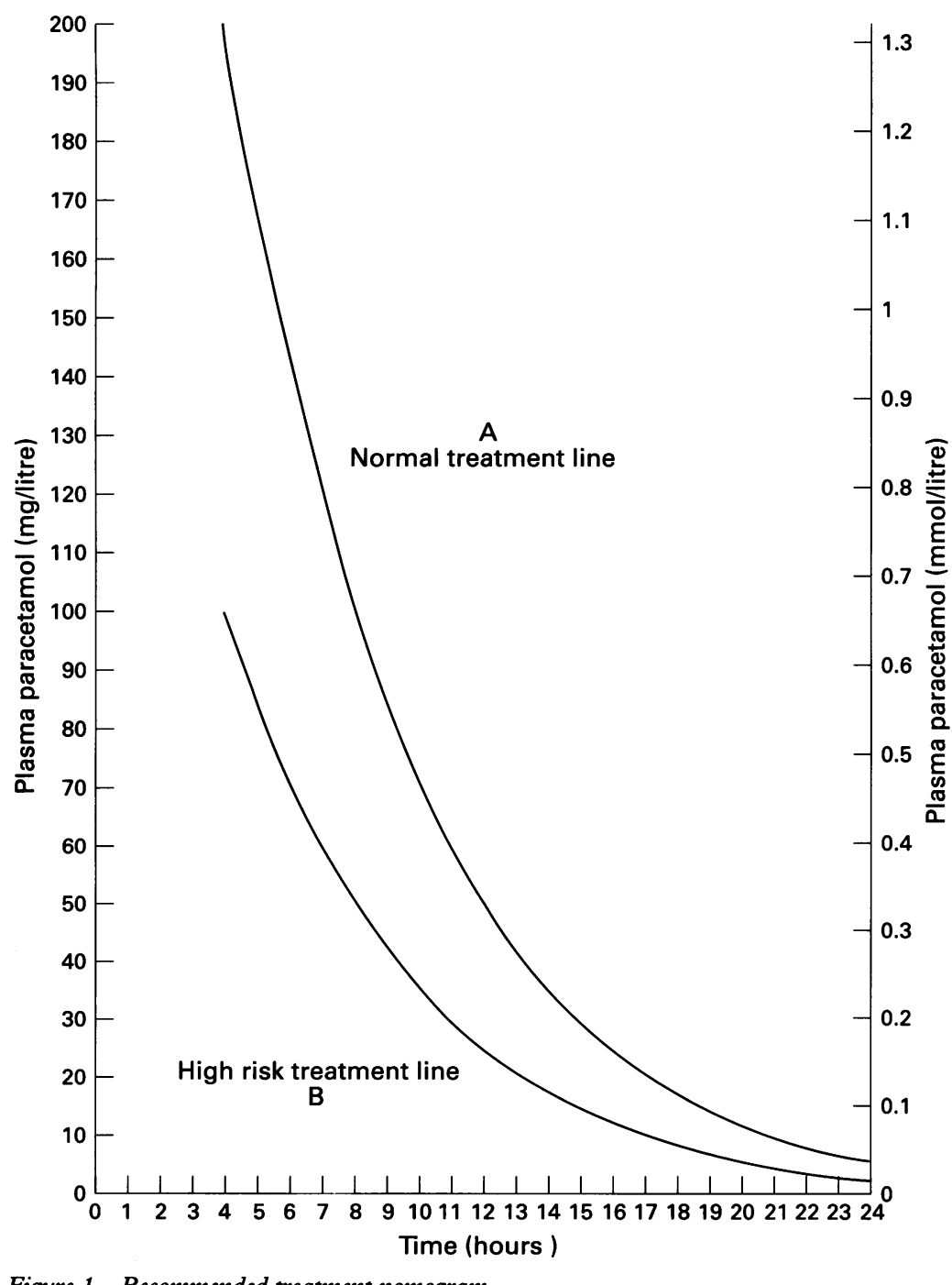

Figure 1 Recommended treatment nomogram. poisons unit or the use of the National Poisons Information Service database (Toxbase). Only five of the centres recommended the administration of $\mathrm{N}$-acetylcysteine up to 24 hours after paracetamol ingestion.

A treatment line was available in 20 of the 24 departments, with no graph displayed in the other four departments. There was considerably variation in the source of the treatment graphs employed, as shown in table 2. Only four of the departments indicated that they would lower the threshold for treatment in patients at particular risk of liver damage.

1995: AFTER CIRCULATION OF NATIONAL

\section{GUIDELINES}

All 24 departments responded. Twenty three of 24 departments now had formal written policies regarding the management of paracetamol toxicity, and 20 used national guidelines. Three of these 20 departments supplemented the national guidelines with in house policies. Three departments relied on in house policies alone. In two of these, differences from national treatment recommendations were minimal, and the issue of treatment up to 24 hours after ingestion was adequately addressed. In the third department it was not clear from the protocol used whether they would give antidote beyond 16 hours postingestion unless the patients' INR (international normalised ratio) values were above 2 .

The single department without a formal written policy employed a copy of data extracted from Toxbase two years previously, which did not at the time recommend antidotal treatment beyond 15 hours. Thus overall, 22 of the 24 departments definitely recommended the administration of $\mathrm{N}$-acetylcysteine up to 24 hours after paracetamol ingestion.

A treatment nomogram was available to staff in all 24 departments (table 3). In 20, this was in the form of the nationally accepted document or a wall chart. Four of these 20 departments also displayed an in house graph. Four departments relied solely on in house graphs. One adequately mirrored the formal nomogram, while three failed to recommend treatment beyond 16 hours postingestion (one contradicting its own written guidelines), with one of these also showing inaccuracies regarding the treatment threshold for patients at special risk of liver damage.

Thus overall all 24 departments have taken account of the effect of high risk situations on treatment threshold, though duplication of information and inconsistencies between policy documents and treatment nomograms could lead to confusion over threshold modifications and timing of treatment in up to seven of the 24 departments.

\section{Discussion}

The impact of formal treatment guidelines is evident from the improvement seen in the availability of management policies and treatment nomograms to the staff working in this sample group of $A \& E$ departments. Most now have access to accurate information on the use of antidotal treatment up to 24 hours after 
paracetamol ingestion and the threshold modifications for circumstances associated with high risk of liver damage. Confusion could, however, arise where in house modifications of policies and nomograms contradict formal documents, or where in house material is used to supplement national guidelines. Although there were no important differences in content between the national and regional guidelines mentioned earlier, the display of more than one of these in a particular department could lead to confusion. At this time there seems little justification for the use of in house guidelines unless they accurately represent the expert opinion on which the national guidelines are based.

A revised wall chart incorporating a treatment nomogram (fig 1) was distributed in June 1995. This takes into account evidence concerning the increased risk of liver damage in patients with conditions causing depletion of glutathione, such as starvation and HIV infection $^{7-9}$ and in staggered paracetamol overdose. ${ }^{10}$ Also considered are changes in the recommendations regarding the timing of gastric emptying and administration of activated charcoal, together with an outline of the management of paracetamol poisoning in children. The information contained in the wall chart is reproduced in the appendix. We would recommend that this information, which could be updated at regular intervals, should form the basis for treatment guidelines for the management of paracetamol poisoning in A\&E departments throughout the United Kingdom. Finally, although research in clinical toxicology is often difficult and heavily reliant on case reports, evidence based guidelines can be developed from the available research and can help to inform clinicians about best practice. The applicability of this approach to other areas within clinical toxicology should be explored.

We thank the directors of the National Poisons Information Service (NPIS) centres for producing the revised guidelines and the British Association for Accident and Emergency Medicine for their advice, comments, and help in distribution. The King's Liver Unit also provided valuable advice in formulating the guidelines and the Paracetamol Information Centre funded the study.

\section{Appendix \\ Management of acute paracetamol over- dose (revised guidelines 1995, National Poisons Information Service)}

GENERAL

Doctors managing paracetamol overdose should be aware that:

1 Hepatocellular necrosis is the major toxic effect and biochemical evidence of maximum damage may not be attained until 72-96 hours after ingestion of the overdose.

2 Any patient should be considered at risk of severe liver damage if he/she has ingested more than $150 \mathrm{mg} / \mathrm{kg}$ body weight, or $12 \mathrm{~g}$ (24 standard tablets) or more in total, whichever is the smaller.

3 Severe liver damage in the context of paracetamol overdose has been defined as a peak plasma alanine aminotransferase
(ALT) activity exceeding $1000 \mathrm{U} /$ litre. Most patients who are clinically unwell will usually have peak ALT activities of several thousands of units per litre.

4 Patients who present 12 hours or longer after ingestion tend to be more severely poisoned and at greater risk of serious liver damage.

5 Patients who regularly consume alcohol in excess of currently recommended amounts, or who regularly take drugs which induce liver microsomal oxidoses (for example, carbamazepine, phenytoin, phenobarbitone, primidone, and rifampicin) are at risk from lower plasma paracetamol concentrations than others (refer to treatment line B).

6 Patients with conditions causing glutathione depletion (for example, malnutrition and HIV infection) may be at risk from lower paracetamol concentrations than others.

7 Acute renal tubular damage and necrosis may also occur, usually in association with hepatocellular necrosis and less commonly in the absence of major liver damage.

\section{TIME FROM INGESTION}

1 Early assessment of the risk of liver damage requires urgent measurement of the patient's plasma paracetamol concentration.

2 Plasma concentrations taken within four hours of ingestion cannot reliably be interpreted because of the possibility of continuing absorption and distribution of the drug.

3 The time interval since ingestion is critical in assessing whether treatment is required, but is often difficult to establish. Detailed questioning of the patient and others is necessary. Patients with acute alcohol intoxication may give inaccurate histories and should be considered for $\mathrm{N}$-acetylcysteine (NAC, acetylcysteine) treatment. If there is doubt about the timing or the need for treatment, treat.

4 Intravenous NAC and oral methionine are effective antidotes for the management of paracetamol overdose. Methionine may be ineffective in patients who have been given oral activated charcoal. NAC is the treatment of choice when patients are vomiting or present more than eight hours after ingestion, when the efficacy of methionine is low.

5 Treatment line A (graph) is not infallible, since the response of individuals to the same amount of paracetamol is highly variable and its validity beyond 15 hours after ingestion is less certain because there are insufficient data from untreated patients.

6 The threshold for treatment of paracetamol overdose with antidotes should be reduced for patients whose liver microsomal oxidases may be induced. We suggest that the plasma paracetamol concentration for treatment at any time after ingestion be $50 \%$ of that recommended for non-induced patients. Line B (graph) is therefore the proposed treatment line for induced patients.

7 The British National Formulary, No 29 (1995) recommends the following dose requirements: 
Acetylcysteine. Dose: by intravenous infusion, in glucose intravenous infusion $5 \%$, initially $150 \mathrm{mg} / \mathrm{kg}$ in $200 \mathrm{ml}$ over $15 \mathrm{~min}$, followed by $50 \mathrm{mg} / \mathrm{kg}$ in $500 \mathrm{ml}$ over $4 \mathrm{~h}$, then 100 $\mathrm{mg} / \mathrm{kg}$ in $1000 \mathrm{ml}$ over $16 \mathrm{~h}$.

Methionine. Dose: by mouth, $2.5 \mathrm{~g}$ initially, followed by three further doses of $2.5 \mathrm{~g}$ every $4 \mathrm{~h}$.

\section{STAGGERED OVERDOSES}

In patients who have taken staggered overdoses, blood levels are meaningless in relation to the treatment graph. These patients should all be considered for treatment with NAC and be discharged only if international normalised ratio (INR) and creatinine are normal.

\section{MANAGEMENT OF PATIENTS WHO PRESENT}

WITHIN 8 H OF INGESTION

1 Consider emptying the stomach or giving activated charcoal if it is thought that more than $150 \mathrm{mg} / \mathrm{kg}$ body weight has been taken and the patient presents within $2 \mathrm{~h}$ of ingestion. These measures are of little value in patients who present more than $2 \mathrm{~h}$ after ingestion.

2 While waiting for measurement of the plasma paracetamol concentration, oral methionine (not NAC) may be given to patients who present within $4 \mathrm{~h}$ of ingestion of a large amount of paracetamol if activated charcoal has not been given.

3 Take blood for urgent estimation of the plasma paracetamol as soon as $4 \mathrm{~h}$ or more have elapsed since ingestion.

4 Assess whether the patient is at special risk of severe liver damage (see GENERAL 5 and 6 above).

5 The risk of the patient developing severe liver damage should then be assessed by considering the plasma paracetamol concentration related to the time from ingestion using treatment line A (graph) if the patient is not at special risk or line $B$ if the patient is.

6 Start treatment with NAC or methionine in patients whose paracetamol concentrations related to time from ingestion lie above the relevant treatment line, if the paracetamol concentration result is not available within 8 $\mathrm{h}$ of ingestion, and if more than $150 \mathrm{mg} / \mathrm{kg}$ body weight or $12 \mathrm{~g}$ in total are thought to have been taken, treatment should be started at once and stopped if the plasma paracetamol concentration subsequently indicates that it is not required.

7 Provided the antidote is started within $8 \mathrm{~h}$ of ingestion, patients may normally be declared fit for discharge from medical care on completion of its administration. There is no merit in keeping them in hospital simply to monitor liver function. Patients should be advised to return if vomiting or abdominal pain develop or recur.

8 The INR and plasma creatinine should be determined on completion of treatment and before discharge.
MANAGEMENT OF PATIENTS WHO PRESENT 8-15 H AFTER INGESTION

1 Urgent action is required because the efficacy of antidotes deteriorates progressively from $8 \mathrm{~h}$ after ingestion.

2 Give NAC immediately without waiting for the result of the plasma paracetamol concentration if it is thought that more than 150 $\mathrm{mg} / \mathrm{kg}$ body weight or a total of $12 \mathrm{~g}$ or more have been ingested.

3 Assess whether the patient is at special risk of severe liver damage (see GENERAL 5 and 6 above).

4 Take blood for estimation of plasma paracetamol concentration for assessment of the risk of the patient developing severe liver damage using treatment line $\mathrm{A}$ (graph) if the patient is not at special risk, or line B if he/she is.

5 Stop administration of the antidote if the level is subsequently found to be below the relevant treatment line (graph).

6 Continue administration if the plasma paracetamol concentration is above the relevant treatment line.

7 At the end of the NAC infusion, a blood sample should be taken to determine the INR and plasma creatinine concentration. If these are normal and the patient is asymptomatic, the risk of severe liver damage is negligible and the patient may be declared it for discharge from medical care.

8 Patients who are symptomatic, or in whom the INR and/or plasma creatinine are abnormal, require further monitoring.

MANAGEMENT OF PATIENTS WHO PRESENT 15-24

H AFTER INGESTION

1 Measure the plasma paracetamol concentration and INR on admission.

2 Give NAC immediately without waiting for the result of the plasma paracetamol concentration measurement, if it is thought that more than $150 \mathrm{mg} / \mathrm{kg}$ body weight or a total of $12 \mathrm{~g}$ or more have been ingested

3 The infusion may be stopped and the patient discharged from medical care if all of the following criteria are met at $24 \mathrm{~h}$ after ingestion:

(a) the patient is asymptomatic;

(b) the INR and plasma creatinine are normal; and

(c) the plasma paracetamol concentration is less than $10 \mathrm{mg} /$ litre.

4 Patients in whom the INR and/or plasma creatinine are abnormal or whose plasma paracetamol concentrations exceed $10 \mathrm{mg} /$ litre at $24 \mathrm{~h}$ after ingestion require further monitoring.

5 All patient should have their INR and plasma creatinine concentration determined before being considered fit for discharge from medical care, whether or not they have received NAC.

MANAGEMENT OF PATIENTS WHO PRESENT MORE THAN 24 H AFTER INGESTION

Management of patients who present more than $24 \mathrm{~h}$ after ingestion of a paracetamol 
overdose is controversial. All should have their INR, plasma creatinine concentrations, and arterial $\mathrm{pH}$ (or hydrogen ion concentration) determined and we recommend that they be discussed with a poisons information centre or a specialist liver or poisons unit.

MANAGEMENT OF CHILDREN

The advice in these guidelines also applies to the management of children. The following guidelines apply to the administration of NAC to children:

Volumes for NAC infusion-paediatric

$20 \mathrm{~kg}$ and over:

(1) $150 \mathrm{mg} / \mathrm{kg} \mathrm{IV}$ infusion over $15 \mathrm{~min}$ in 100 $\mathrm{ml} 5 \%$ glucose.

(2) Then $50 \mathrm{mg} / \mathrm{kg} \mathrm{IV}$ infusion in $250 \mathrm{ml} 5 \%$ glucose over $4 \mathrm{~h}$.

(3) Then $100 \mathrm{mg} / \mathrm{kg} \mathrm{IV}$ infusion in $500 \mathrm{ml} \mathrm{5 \%}$ glucose over $16 \mathrm{~h}$.

Under $20 \mathrm{~kg}$ :

Volumes for infusion of the above doses are the responsibility of the prescriber, and should be based on the daily maintenance requirements of the child by weight.

\section{SPECIALIST ADVICE ON PATIENT WITH SEVERE LIVER DAMAGE}

Patients who develop severe liver damage may merit discussion with a specialist liver unit (not necessarily a liver transplant unit). Such discussions are likely to be of greater benefit if they are held early. Patients in this category include those who have an INR greater than 3.0, a raised plasma creatinine, evidence of acidosis or encephalopathy, hypotension (mean arterial blood pressure less than $60 \mathrm{~mm} \mathrm{Hg}$ ), or pre-existing liver disease.

ADVERSE REACTIONS TO ACETYLCYSTEINE AND THEIR MANAGEMENT

Acetylcysteine can cause adverse effects which may be localised to the area surrounding the infusion site or more generalised, and usually occur within the first $30 \mathrm{~min}$ of administration when large amounts of the antidote are being given rapidly. They include nausea, flushing, itching, erythematomacular rashes, urticaria, angio-oedema, bronchospasm, and rarely hypotension or hypertension. Infusion of NAC should be stopped and an antihistamine given. Once the adverse effects have settled, infusion can usually be resumed at the lowest infusion rate $(100 \mathrm{mg} / \mathrm{kg}$ over $16 \mathrm{~h})$.

For further advice contact the poisons information services:

Belfast 01232240503

Birmingham 01215543801

Cardiff 01222709901

Dublin 8379964 or Dublin 8379966

Edinburgh 01312292477 or 01312282441

(viewdata)

Leeds 01132430715

London 01716359191 or 01719555095

Newcastle 01912325131

1 Paracetamol Information Centre. London, 1996.

2 Smith JAE, Hine ID, Beck P, Routledge PA. Paracetamol toxicity: is enzyme induction important? Hum Exp Toxicol 1986;5:383-5.

3 Bray GP, Mowat C, Muir DF, Tredger JM, Williams R. The effect of chronic alcohol intake on prognosis and outcome in paracetamol overdose. Hum Exp Toxicol 1991;10: in parace

4 Parker D, White TP, Paton D, Routledge PA. Safety of late acetylcysteine treatment in paracetamol poisoning. Hum

5 Harrison PM, Keays R, Bray GP, Alexander GJM, Williams Harrison PM, Keays R, Bray GP, Alexander GJM, Williams hepatic failure by late administration of acetylcysteine. Lancet 1990;335:1572-3.

6 Keays R, Harrison PM, Wendon JA, Forbes A, Gove C, Alexander GJM, et al. Intravenous acetylcysteine in paracetamol induced fulminant hepatic failure: a prospective controlled trial. BMJ 1991;303:1026-9.

7 Eriksson LS, Broome U, Kalin M, Lindholm M. Hepatotoxicity due to repeated intake of low doses of paracetamol. J Intern Med 1992;231:567-70.

8 Buhl R, Jaffe HA, Holroyd KJ, Wells FB, Mastrangeli A, Saltini $C$, et al. Systemic glutathione deficiency in symptom-free HIV-seropositive individuals. Lancet 1989 ii:1294-8.

9 Henry JA. Glutathione and HIV infection [letter]. Lancet 1990;335:235-6.

10 Douidoar SM, Asl-Khalil I, Hakersang RW. Severe hepatotoxicity, acute renal failure, and pancytopenia in a young child after repeated acetaminophen overdosing. Clin Pediatr 1994;33:42-5. 